\title{
Characteristics of Graphene Nanoplatelets anode in advanced lithium-ion battery using ionic liquid added by carbonate electrolyte
}

\author{
Marco Agostini ${ }^{1}$, Laura Giorgia Rizzi ${ }^{2}$, Giulio Cesareo ${ }^{2}$, Valeria Russo ${ }^{3}$ and Jusef Hassoun ${ }^{1 *}$ \\ ${ }^{1}$ Sapienza University of Rome, Chemistry Department, Piazzale Aldo Moro 5, 00185, Rome, Italy \\ ${ }^{2}$ Directa Plus SpA, Via Cavour 2, 22074, Lomazzo, Como, Italy \\ ${ }^{3}$ Department of Energy and NEMAS, Politecnico di Milano, via Ponzio 34/3, I-20133 Milan, Italy
}

*Corresponding authors: jusef.hassoun@uniroma1.it

\begin{abstract}
Keywords: graphene nanoplatelets; high performance anode; $\mathrm{Py}_{1,4}$ TFSI-LiTFSI ionic liquid electrolyte; safe lithium-ion battery.
\end{abstract}

\begin{abstract}
Herein, we report a Cu-supported, graphene nanoplatelets (GNPs) electrode as high performance anode in lithium ion battery. The electrode precursor is an easy-to-handle aqueous ink cast on cupper foil and following dried in air. The scanning electron microscopy evidences homogeneous, micrometric flakes-like morphology. Electrochemical tests in conventional electrolyte reveal a capacity of about $450 \mathrm{mAh} \mathrm{g}^{-1}$ over 300 cycles, delivered at a current rate as high as $740 \mathrm{~mA} \mathrm{~g}^{-1}$. The graphene-based electrode is characterized using a Py ${ }_{1,4}$ TFSI-LiTFSI ionic liquid-based solution added by EC:DMC. The Li-electrolyte interface is investigated by galvanostatic and potentiostatic techniques as well as by electrochemical impedance spectroscopy, in order to allow the use of the graphene-nanoplatelets as anode in advanced lithium-ion battery. Indeed, the electrode is coupled with a $\mathrm{LiFePO}_{4}$ cathode in a battery having a relevant safety content, due to the IL-based electrolyte that is characterized by an ionic conductivity of the order of $10^{-2} \mathrm{~S} \mathrm{~cm}^{-1}$, a transference number of 0.38 and a high electrochemical stability. The lithium ion
\end{abstract}


battery delivers a capacity of the order of $150 \mathrm{mAh} \mathrm{g}^{-1}$ with an efficiency approaching $100 \%$, thus suggesting the suitability of graphene nanoplatelets anode for application in advanced configuration energy storage systems.

\section{Introduction}

The rapid development of the electric vehicles market triggered increasing energy density demand and large interest on alternative materials for lithium-ion battery, in replacement of the conventional lithium cobalt oxide cathode and graphite anode. Among the negative electrodes, lithium metal alloys, such as lithium-tin $(\mathrm{Li}-\mathrm{Sn})^{\mathbf{1 - 3}}$ and lithium silicon $(\mathrm{Li}-\mathrm{Si})^{\mathbf{4 - 1 0}}$, and most recently, graphene and chemically modified graphene have been considered as promising high performance electrode. ${ }^{11-18}$ A single-layer graphene is zero-gap semi-metal, with high electronic conductivity, i.e. approaching that of metals. Graphene may be synthesized as transparent electrode, well competing with the most expensive commercial ITO (indium tin oxide). ${ }^{\mathbf{1 9 - 2 0}}$ Moreover, the strong in-plane C-C $\sigma$-bonds hold up a great enhancement of the Young's modulus, fracture strength ${ }^{21}$ and hardness, in comparison to typical carbon steel. ${ }^{\mathbf{2 2 - 2 4}}$ Further studies, demonstrated the suitability of graphene as negative electrode in replacement of the commercial graphite anode in lithium-ion battery. Indeed, it has been reported that graphene can accommodate Li-ions on both sides ${ }^{25}$, thus giving rise to a capacity two times higher than that of graphite, i.e. $744 \mathrm{mAh} \mathrm{g}^{-1}$ vs. $372 \mathrm{mAh} \mathrm{g}^{-1}$, corresponding to the formation of $\mathrm{LiC}_{3}$ instead of $\mathrm{LiC}_{6}$, respectively. However, an electrode formed by single graphene layer may deliver a very limited practical capacity due to an extremely low tap-density, not suitable for battery application. ${ }^{\mathbf{2 6 , 2 7}}$ Furthermore, recent studies evidenced that a graphene single layer follows only in part the predicted reaction mechanism with lithium, due to strong repulsion forces between the $\mathrm{Li}^{+}$ions at both sides, while few layers may have satisfactory electrochemical performance in terms of Li-uptake mechanism and delivered capacity. ${ }^{\mathbf{2 8 , 2 9}}$ These properties triggered increasing interest on electrodes formed by multiple graphene layers, instead of single layer, that are expected to have a higher mass density and practical capacity. Graphene 
nanoplatelets represent a hybrid system offering a variety of exploitable properties and being already deliverable on an industrial scale (tones/year). As far as it concerns, the graphene nanoplatelets herein reported, following indicated by the acronym GNPs, refer to a mix of particles of various sizes, differing both in terms of lateral dimension and thicknesses. Indeed, the GNPs reported here are characterized by a lateral dimension ranging from $200 \mathrm{~nm}$ to $5 \mu \mathrm{m}$, and thickness between $0.34 \mathrm{~nm}$ and $8 \mathrm{~nm}$. The nanoplatelets are characterized by low lattice-defect ratio and absence of functional groups. This characteristic morphology, and the contemporary high crystals quality, make our GNPs suitable material for battery application, i.e. providing a satisfactory tapdensity, an enhanced Li-uptake mechanisms and a good transport properties.

Despite several promising theoretical predictions, only few examples of graphene application in efficient lithium-ion battery have been so far reported. ${ }^{\mathbf{1 8 , 3 0 - 3 2}}$ Furthermore, graphenebased electrodes evidenced several issues in lithium battery, such as the very high irreversible capacity during the first cycles, due to an irregular solid electrolyte interphase (SEI) film formation, a severe capacity decay during cycling and the a reaction mechanism still to be verified. ${ }^{\mathbf{3 2}}$

Herein, we reported a first example of $\mathrm{Cu}$-supported graphene nanoplatelets anode in an efficient lithium ion battery using $\mathrm{LiFePO}_{4}$ cathode and non-flammable, N-butyl-N-methylpyrrolidiniumbis (trifluoromethanesulfonyl) imide, lithium-bis(trifluoromethanesulfonyl)imide $\left(\mathrm{Py}_{1,4}\right.$ TFSI-LiTFSI $)$ electrolyte added by a proper ratio of EC:DMC. ${ }^{33}$ The EC-DMC addition within the electrolyte was aimed to reduce the viscosity of the solution, thus favoring the electrodeelectrolyte interface properties and enhancing the Li-transference number. IL- based electrolytes are presently characterized by high cost, however it is expected that commercial diffusion of this promising electrolyte may significantly reduce the cost to a level comparable to common, carbonate-based electrolytes. The novelties offered by our cell comprise: 1) the use of graphene nanoplatelets already produced on an industrial scale; 2) a simple anode preparation procedure consisting in a direct casting of a water-based GNPs dispersion, thus avoiding slurry preparation and organic-solvent based processing; 3) the use of non-flammable and intrinsically safe IL-based 
electrolyte; 4) a very promising electrochemical cell performances. Even remarking that an accurate

cost-analysis is not available at the present stage, we may assume a reduction of the anode side cost due to the use of a ready-to-use solution for electrode preparation, without the employment of binder, solvents, conducting agent or complex fabrication procedures. All these features, and the good stability of the cathode, allowed the achievement of high efficiency and energy density, as well as remarkable safety content, making the cell of sure interest for the lithium-ion battery community.

\section{Results and discussion}

The graphene nanoplatelets water-based dispersion used in this work has been prepared by Directa Plus following the method described within the international patent application. ${ }^{\mathbf{3 4}}$ The dispersion has a GNPs concentration of $200 \mathrm{~g} / \mathrm{L}$ which is stabilized by the presence of an anionic surfactant, in a concentration of $20 \mathrm{~g} / \mathrm{L}$. GNPs have a lateral dimension on average below $5 \mu \mathrm{m}$ and a thickness on average below $8 \mathrm{~nm}$. The graphene nanoplatelets structure and morphology have been characterized by SEM, Raman and TGA techniques, respectively. Figure 1a reports the scanning electron microscopy (SEM) image of the GNPs water-based dispersion deposited on a $\mathrm{SiO}_{2}$ substrate. The image shows a lateral dimension of the GNPs within the micrometers range and a thickness within the nanometers range. The aspect-ratio (lateral dimension versus thickness) shows an average extending up to 1000 . Figure 1b, reporting the Raman spectrum, highlights remarkable crystallinity and low defectivity of the GNPs that is confirmed by the narrow G peak at $1583 \mathrm{~cm}^{-1}$ and by the small D peak, associated to defects and edges of the platelets. The low intensity-ratio between the two previous peaks, i.e. an $\mathrm{I}(\mathrm{D}) / \mathrm{I}(\mathrm{G})$ lower than 0.2 , likely suggests a reduced amount of lattice defects, however further experiments are required in order to clarify this aspect. The Raman spectrum also reveals a $2^{\text {nd }}$ order peak with two-components (already known as 2D-peak), revealing the pristine nature of the GNPs. ${ }^{35}$ The intensity ratio between the two components confirms that our system is mainly composed by few layers. ${ }^{\mathbf{3 6}}$ Figures $1 \mathrm{c}$ and d, 
reporting the TGA under air and the corresponding derivative curve of the GNPs water-dispersion, show a thermal stability extending up to $500{ }^{\circ} \mathrm{C}$. The first weight decay, at about $100{ }^{\circ} \mathrm{C}$, is attributed to the water loss, while the peak at about $550{ }^{\circ} \mathrm{C}$ is most likely due to the oxidative degradation of the carbon matrix, as indeed evidenced by the inset of Fig. 1c.

We have preliminary characterized the GNP anode in LP30 electrolyte (EC-DMC 1:1, $\left.\mathrm{LiPF}_{6} 1 \mathrm{M}\right)$ in order to provide an evaluation of the electrochemical behavior in a bare, conventional electrolyte considered as a standard condition. Figure 1e shows the galvanostatic voltage profiles of the lithium half-cell cycled at a current as high as $744 \mathrm{~mA} \mathrm{~g}^{-1}$, corresponding to the $1 \mathrm{C}$-rate based on graphene electrode weight, theoretically following the reaction mechanism: $2 \mathrm{Li}^{+}+2 \mathrm{e}^{-}+\mathrm{C}_{6}=$ $2 \mathrm{Li}_{3} \mathrm{C}{ }^{25}$ To be noticed that the used current corresponds to a $2 \mathrm{C}$-rate when referred to a conventional graphite electrode. The lithium cell delivers a capacity of about $715 \mathrm{mAh} \mathrm{g}^{-1}$ during the first discharge that is stabilized to a value of about $460 \mathrm{mAh} \mathrm{g}^{-1}$ during the following cycles, i.e. a capacity exceeding by $25 \%$ the theoretically value ascribed to conventional graphite (i.e. 370 $\left.\mathrm{mAh} \mathrm{g}^{-1}\right)$. The significant irreversible capacity observed during the first cycle is commonly attributed to side reactions induced by functional groups, oxygen atoms, hydrogen atoms and eventual impurities at the carbon electrode surface, ${ }^{37-39}$ and to electrolyte decomposition with consequent solid-electrolyte interface (SEI) formation. ${ }^{40}$ We already demonstrated in previous papers that irreversible capacity of the graphene-based materials may be efficiently reduced by direct treatment with lithium metal (see also experimental section), thus making the electrodes suitable for application in efficient lithium-ion battery. ${ }^{18,32}$ Despite the highly defective materials previously studied have greatly promoted the Li-uptake within the graphene, i.e. leading to a capacity approaching the theoretical value of $744 \mathrm{mAh} \mathrm{g}^{-1}$, they were however characterized by a very large irreversible capacity during the first cycles. ${ }^{18,32}$ This is considered a severe issue and may be addressed by several strategies including the reduction of the $\mathrm{I}(\mathrm{D}) / \mathrm{I}(\mathrm{G})$ ratio, as indeed reported in this work. The GNPs electrode is herein prepared by using an easy-to-handle casting procedure and characterized by higher loading in respect to the typical graphene. This is considered a 
remarkable advantage in view of the application of graphene-based electrode in lithium-ion battery.

Figure 1f, reporting the charge/discharge cycling behavior of the cell in the conventional electrolyte, reveals a reversible capacity of about $460 \mathrm{mAh} \mathrm{g}^{-1}$ with a very stable trend, extending up to 200 cycles, and of about $390 \mathrm{mAh} \mathrm{g}^{-1}$ up to 300 cycles and a Coulombic efficiency approaching $99 \%$ within steady state condition.

\section{Figure 1}

Following, the GNPs electrode has been studied in a Py ${ }_{14}$ TFSI-LiTFSI ionic liquid electrolyte solution added by the $30 \%$ of EC-DMC that is characterized by lower flammability in comparison to the bare carbonate electrolyte and, contemporary, higher electrochemical performances in respect to a bare $\mathrm{Py}_{14}$ TFSI-LiTFSI IL-electrolyte. Figure 2 reports a comparison of the characteristics of the two electrolytes in terms of ionic conductivity, electrochemical stability and lithium transference number. The Arrhenius plots of the two solutions (Figure 2a) show the effect of the EC-DMC-addition on the conductivity value that increases from $10^{-3} \mathrm{~S} \mathrm{~cm}^{-1}$ to $10^{-2} \mathrm{~S}$ $\mathrm{cm}^{-1}$, at $25^{\circ} \mathrm{C}$, considered suitable for application in high performance lithium-ion battery. Figure $2 \mathrm{~b}$ shows the time evolution of the overall resistance of Li-symmetric cells and, in inset, the corresponding impedance spectra, of the pristine and the EC-DMC added electrolytes. The pristine electrolyte shows a typical resistance growth during the initial 10 hours, followed by a drop associated to the SEI film formation, partial dissolution and final stabilization to a value of about $250 \Omega$, while the EC-DMC-added electrolyte shows a slight growth during the initial 5 hours to a final, stable resistance of about $200 \Omega$, thus suggesting the formation of an enhanced SEI film compared to the pure IL-solution. The lithium plating-stripping profiles reported in Figure 2c reveal a polarization limited to few $\mathrm{mV}$ for both electrolytes, as clearly evidenced by the inset reporting the magnification of the curves. However, voltage-spikes, most likely due to dendrite formation in the cell using pure IL-electrolyte, are observed. Instead, the absence of dendrite formation within the cell using the EC:DMC-added electrolyte confirms its favorable interface with lithium electrode and further supports the suitability of the selected solution for application in lithium battery. The 
optimized SEI formed at the lithium side of the cell using the modified, carbonate-added ILelectrolyte is finally confirmed by the lower polarization in comparison to the bare IL electrolyte (Fig. 2c), in full agreement with the lower resistance observed in Fig. $2 b$.

Figure $2 \mathrm{~d}$ shows the curves used to determine the lithium transference number of the pristine IL (black) and the EC-DMC added (red) electrolytes, according to the Bruce-Vincent method, i.e. the time evolution of the overall resistance of a $\mathrm{Li}$-symmetric cell and, in inset, the corresponding impedance spectra. ${ }^{41}$ The lithium transference number, $\mathrm{t}_{\mathrm{Li}}{ }^{+}$, is calculated to be of about 0.25 for the pristine IL electrolyte and of 0.38 for the EC-DMC added one. The increase of the lithium transference number by addition of EC-DMC to the ionic liquid is most likely due to the effect of a reduced viscosity of the solution in addition to a more favorable solvation of the lithium ions. The enhancement of the ionic conductivity, SEI stability, Li-transference number and compatibility with lithium metal, finally suggest the full compatibility of the studied electrolyte for application in efficient, high performances lithium-ion battery. Furthermore, the low impedance values observed in figure 2 as well as the stability of the electrode-electrolyte interphase revealed by the impedance evolution during time are expected to directly reflect in an optimized behavior of the half and full cells both in terms of low cell polarization and of stability (see following paragraph).

\section{Figure 2}

The Py ${ }_{14}$ TFSI-LiTFSI, EC-DMC-added solution has been then selected as the electrolyte to be characterized both in half lithium cell using the GNPs electrode and in full cell combining the new anode together with a conventional, safe and low cost $\mathrm{LiFePO}_{4}$ cathode. Figure 3a, reporting the steady-state galvanostatic voltage profiles of the lithium half-cell using the selected electrolyte and the GNPs electrode, used to verify the suitability of the anode within the new electrolyte, evidences a reversible capacity of about $450 \mathrm{mAh} \mathrm{g}^{-1}$ and an efficiency increasing from $84 \%$ to $95 \%$ by the ongoing of cycles. The lower efficiency of the cell using the new electrolyte in respect to conventional LP30 (see Fig.1e), may be most likely attributed to the already reported possible decomposition of the Py ${ }_{14}$ TFSI-LiTFSI electrolyte in the low voltage region. ${ }^{42}$ Furthermore, the 
GNPs half-cell using the IL-based electrolyte shows a lower rate capability in respect to the one using the LP30 electrolyte, due to the lower lithium transference number.

Following, the high capacity GNPs electrode has been combined with a $\mathrm{LiFePO}_{4}$ cathode using the IL-based electrolyte. The cathode is bare electrode, already characterized in LP30 (data not reported here). Figure $3 b$, reporting the galvanostatic voltage profiles of a lithium half-cell using a $\mathrm{LiFePO}_{4}$ cathode in IL-based electrolyte, highlights a stable capacity of about $150 \mathrm{mAh} \mathrm{g}^{-1}$ and a slight increase of the charge-discharge polarization upon cycling, most likely attributed to the increase of the cell polarization due to the SEI film formation at the lithium metal side and to a minor ILoxidative decomposition at the higher potentials. Figure $3 \mathrm{c}$ compares the capacity of the $\mathrm{Cu}$ supported GNPs (bottom, red line) and of the $\mathrm{LiFePO}_{4}$ (up, black line). The anode can operate following a semi-plateau with a specific capacity of $460 \mathrm{mAh} \mathrm{g}^{-1}$ and average voltage value of about $0.2 \mathrm{~V}$ vs. $\mathrm{Li}^{+} / \mathrm{Li}$, while the $\mathrm{LiFePO}_{4}$ shows a reversible capacity of $150 \mathrm{mAh} \mathrm{g}^{-1}$ and average working voltage of about $3.5 \mathrm{~V}$ vs. $\mathrm{Li}^{+} / \mathrm{Li}$. The above reported numbers require a proper cell balance during coupling the GNPs anode with the $\mathrm{LiFePO}_{4}$ cathode, see experimental section, in order to ensure efficient lithium ion battery operation. Figure $3 \mathrm{~d}$ reports the galvanostatic voltage profile of the above full lithium-ion battery cycled at $\mathrm{C} / 10$ rate using the Py $\mathrm{y}_{14}$ TFSI-LiTFSI, ECDMC-added electrolyte. The figure shows a cell working voltage of about $2.4 \mathrm{~V}$ and a stable capacity of $150 \mathrm{mAh} \mathrm{g}^{-1}$, with an estimated theoretical energy density of $360 \mathrm{Wh} \mathrm{kg}^{-1}$. The figure clearly evidences a voltage shape resulting by the combination of GNPs anode and $\mathrm{LiFePO}_{4}$ cathode profiles, in particular in the region ranging between $3 \mathrm{~V}$ and $1.5 \mathrm{~V}$ during the discharge. The cell reveals a minor increase of the polarization during cycling, i.e. a trend already observed for half-cell using the $\mathrm{LiFePO}_{4}$ cathode.

\section{Figure 3}




\section{Conclusions}

Graphene and graphene oxide based anodes have been widely exploited in lithium-half cell systems, revealing a stable capacity ranging between 300 to $600 \mathrm{mAhg}^{-1}$ for over 100 cycles. ${ }^{43,44}$ However, only few works demonstrated the practical use of graphene in the replacement of the Li-metal anode in Li-full cell. ${ }^{\mathbf{8} 31}$ Herein, we developed a graphene nanoplatelets (GNPs) electrode able to deliver a stable capacity of about $450 \mathrm{mAh} \mathrm{g}^{-1}$ (exceeding by $25 \%$ the conventional graphite capacity) for over 300 cycles in conventional electrolyte. Furthermore, we demonstrated the suitability of GNPs in an efficient Li-ion battery using a proper balance, and originally employing an IL-based electrolyte. The lithium-ion battery originally combines the high performances anode, a safe $\mathrm{Py}_{1,4}$ TFSI-LiTFSI-EC-DMC electrolyte and a low cost, environmentally friendly $\mathrm{LiFePO}_{4}$ cathode. The new system evidences very promising performances with a stable capacity of about $150 \mathrm{mAh} \mathrm{g}^{-}$ ${ }^{1}$ delivered at $2.4 \mathrm{~V}$. Despite needing further optimization, in particular in terms of cycle life, the cell herein proposed represents a suitable example demonstrating the practical use of graphene-based anode in lithium-ion battery.

\section{Experimental}

The $\mathrm{Cu}$-supported anode film has been prepared by casting a slurry of the graphene nanoplatelets solution at $70{ }^{\circ} \mathrm{C}$ with a maximum final thickness of $10 \mu \mathrm{m}$, and obtaining an active material loading of about $1.0 \mathrm{mg} \mathrm{cm}^{-2}$. The $\mathrm{LiFePO}_{4}$ cathode was prepared according previous papers. ${ }^{45,46}$ The electrode film was prepared by blending the active material (80\%), super P carbon (10\%, Timcal) and polyvinylidene fluoride (10\%, Kynar Flex) in NMP (Sigma Aldrich Ltd.); the slurry has been casted on aluminum foil and dried overnight under vacuum condition at $110{ }^{\circ} \mathrm{C}$. The active material loading was of about $3 \mathrm{mg} \mathrm{cm}^{-2}$. Prior to full lithium ion cell assembling, the $\mathrm{Cu}$ supported graphene nano-platelets electrode was partially activated by contacting it with a $\mathrm{Li}$ foil wet by LP30 solution (EC:DMC 1:1, $\mathrm{LiPF}_{6} 1 \mathrm{M}$, Merck) for 30 minutes and then washed by DMC 
solution, following removed by vacuum for $20 \mathrm{~min}$. . The XRD measurement was carried out by using a Rigaku D-max with $\mathrm{Cu} \mathrm{K} \alpha$ radiation source with $2 \theta$ ranging from $20^{\circ}$ to $50^{\circ}$. Micro-Raman measurements have been performed by using a Renishaw InVia spectrometer, equipped by an $\mathrm{Ar}^{+}$ laser of $514.5 \mathrm{~nm}$ wavelength, with limited power and proper focusing conditions to avoid damage or modifications of the sample. The galvanostatic cycling tests were carried out by a Maccor battery tester using a coin-type cell for the lithium half-cell and a Swagelok type cells for the lithium-ion battery, within a $0.01 \mathrm{~V}-2.0 \mathrm{~V}$ voltage range for the GNPs anode, $4 \mathrm{~V}-2.5 \mathrm{~V}$ for the LFP cathode and $4 \mathrm{~V}-1.5 \mathrm{~V}$ for the lithium-ion battery. The electrolytes used in this work has been soaked in a glass fiber separator (Whatman). The lithium/electrolyte interface was studied by Electrochemical Impedance Spectroscopy (EIS), applying a $10 \mathrm{mV}$, AC amplitude signal to a Li symmetrical cell in the $500 \mathrm{KHz}-100 \mathrm{mHz}$ frequency range. The Lithium transference number was obtained by using the Bruce-Vincent equation, applying $\mathrm{AC}$ and $\mathrm{DC}$ polarization to a lithium symmetrical cell. The ionic conductivity has been studied by EIS using a blocking electrode configuration, i.e. SS/electrolyte/SS and a $500 \mu \mathrm{m}$ thick Teflon-O-ring of $8 \mathrm{~mm}$ internal diameter and $16 \mathrm{~mm}$ external. The AC signal applied was of $10 \mathrm{mV}$ amplitude in the frequency range of $100 \mathrm{kHz}-100 \mathrm{~Hz}$. The stripping/deposition measurements were performed by using a galvanostatic current of $0.1 \mathrm{~mA} \mathrm{~cm}^{-2}$ with a time limit of 1 hour. All the above tests were carried out using a VSP Biologic instrument.

The IL solution was prepared by dissolving $0.2 \mathrm{~mol}$ of LiTFSI (Solvionic) in $1 \mathrm{~kg}$ of Py $\mathrm{y}_{1,4} \mathrm{TFSI}$ (Solvionic).

\section{Acknowledgments}

This work was presented at the International conference on Ionic Liquid for Electrochemical Devices (ILED 2014, Rome, Italy), and supported by the Italian project "Regione Lazio" at Sapienza University of Rome, Chemistry Department. Directa Plus, Como, Italy provided the Graphene nano-platelets. The authors wish to thank Professor Bruno Scrosati, President of Elettrochimica ed Energia, Rome, Italy for the helpful discussion. SEM image has been performed 
in "L-NESS Politecnico di Milano" while TGA analysis has been performed in "Dipartimento di Scienza Applicata e Tecnologia, Politecnico di Torino".

\section{References}

[1] M. Wachtler, M. Winter, J.O. Besenhard; J. Power Sources, 2002, 105, 151.

[2] G. Derrien, J. Hassoun, S. Panero, B Scrosati, Adv. Mater., 2007, 19, 2336.

[3] J. Hassoun, G. Derrien, S. Panero, B. Scrosati; Adv. Mater., 2008, 20, 3169.

[4] A. Wilson, B. Way, J. Dahn, T. Van Buuren; J. Appl. Phys., 1995, 77, 2363.

[5] S. Bourderau, T. Brousse, D.M Schleich; J. Power Sources, 1999, 81, 233.

[6] W.J. Weydanz, M. Wohlfahrt-Mehrens, R.A. Huggins; J. Power Sources, 1999, 81, 237.

[7] J.O. Besenhard, J. Yang, M. Winter; J. Power Sources, 1997, 68, 87.

[8] P.Limthongkul, Y.-I. Jang, N.J. Dudney, Y.-M. Chiang; Acta Mater., 2003, 51, 1103.

[9] H. Wu, G. Chan, J.W. Choi, I. Ryu, Y. Yao, M.T. Mcdowell, S.W. Lee, A. Jackson, Y, Yang, L. Hu, Y. Cui; Nat. Nanotechnol., 2012, 7, 310.

[10] H. Nara, T. Yokoshima, T. Momma, T. Osaka; Energy Environ. Sci., 2012, 5, 6500.

[11] E. Yoo, J. Kim, E. Hosono, H. Zhou, T. Kudo, I. Honma; Nano Lett., 2008, 8, 2277.

[12] D. Pan, S. Wang, B. Zhao, M. Wu, H. Zhang, Y. Wang, Z. Jiao; Chem. Mater., 2009, 21, 3136.

[13] P. Guo, H. Song, X. Chen; Electrochemistry Communications, 2009, 11, 1320.

[14] P. Lian, X. Zhu, S. Liang, Z. Li, W. Yang, H. Wamg; Electroch. Acta, 2010, 55, 3909.

[15] C. Xu, B. Xu, Y. Gu, Z. Xiong, J. Sun, X.S. Zhao; Energy Environ. Sci., 2013, 6, 1388.

[16] G. Wang, X. Shen, J. Yao, J. Park; Carbon, 2009, 47, 2049.

[17] O.A. Vargas, A. Caballero, J. Morales; Nanoscale, 2012, 4, 2083.

[18] O.A. Vargas, A. Caballero, J. Morales, G.A. Elia, B. Scrosati, J. Hassoun; Phys. Chem. Chem. Phys., 2013, 15, 20444.

[19] S.G.S.V.P. Gusynin, J.P. Carbotte; Phys. Rev. Lett., 2006, 96, 256802. 
[20] S. Bae, H. Kim, Y. Lee, X. Xu, J.-S. Park, Y. Zheng, J. Balakrishnan, T. Lei, H. Ri Kim, Y.I. Song, Y.-J. Kim, K.S. Kim, B. Ozyilmaz, J.-H. Ahn, B.H. Hong, S. Iijima; Nat. Nanotechnol., 2010, 5,574 .

[21] Y.W. Zhu, S. Murali, W.W. Cai, X.S. Li, J.W. Suk, J.R. Potts, R.S. Ruoff; Adv. Mater., 2010, $22,3906$.

[22] A.R. Ranjbartoreh, B. Wang, X.P. Shen, G.X. Wang; J. Appl. Phys., 2011, 109, 014306.

[23] K.S. Kim, Y. Zhao, H. Jang, S.Y. Lee, J.M. Kim, J.H. Ahn, P. Kim, J.Y. Choi, B.H. Hong; Nature, 2009, 457, 706.

[24] C. Lee, X. Wei, J.W. Kysar, J. Hone; Science, 2008,321, 385.

[25] J.R. Dahn, T. Zheng, Y.H. Liu, J.S. Xue; Science, 1995, 270, 590.

[26] J. Liu; Nat. Nanotechnol., 2014, 9, 739.

[27] R. Raccichini, A.Varzi, S.Passerini, B.Scrosati; Nat. Mater., 2015, DOI:10.1038/NMAT4170

[28] E. Pollak, B. Geng, K.J. Jeon, I.T. Lucas, T.J. Richardson, F. Wang, R, Kostecki; Nano Lett., 2010, 10, 3386.

[29] C. Uthaisar, V. Barone; Nano Lett., 2010, 10, 2838.

[30] P. Lian, X. Zhu, S. Liang, Z. Li, W. Yang, H. Wang; Electrochim. Acta, 2010, 55, 3909.

[31] P. Guo, H. Song, X. Chen; Electrochem. Commun., 2009, 11, 1320.

[32] J. Hassoun, F. Bonaccorso, M. Agostini, M. Angelucci, M.G. Betti, R. Cingolani, M. Gemmi, C. Mariani, S. Panero, V. Pellegrini, B. Scrosati; Nano Lett., 2014, 14, 4901.

[33] M. Armand, F. Endres, D.F. MacFarlane, H. Ohno, B. Scrosati; Nat. Mater., 2009, 8, 621.

[34] Patent Application: WO 2014/135455 A1

[35] A. C. Ferrari, J. C. Meyer, V. Scardaci, C. Casiraghi, M. Lazzeri, F. Mauri, S. Piscanec, D. Jiang, K. S. Novoselov, S. Roth, and A. K. Geim; Phys. Rev. Lett., 2006, 97, 187401.

[36] A.C. Ferrari; Solid State Commun., 2007, 143, 47.

[37] F. Bonino, S. Brutti, P. Reale, B. Scrosati, L. Gherghel, J. Wu, K. Müllen; Adv. Mater., 2005, $17,743$. 
[38] A. Caballero, L. Hernán, J. Morales; ChemSusChem, 2011, 4, 658.

[39] Y. Hu, P. Adelhelm, B. M. Smarsly, S. Hore, M. Antonietti, J. Maier; Adv. Funct. Mater., 2007, $17,1873$.

[40] R. Fong, U. von Sacken, J.R. Dahn; J. Electrochem. Soc., 1990, 137, 2009.

[41] Evans, C.A. Vincent, P.G. Bruce; Polymer, 1987, 28, 2324.

[42] J. Hassoun, A. Fernicola, M.A. Navarra, S. Panero, B. Scrosati; J. Power Sources, 2010, 195, 574.

[43] L. Wan, Z. Ren, H. Wang, G. Wang, X. Tong, S. Gao, J. Bai; Diamond Relat. Mater., 2011, 20, 756.

[44] G. Wang, B. Wang, X. Wang, J. Park, S. Dou, H. Ahn, K. Kim; J. Mater. Chem., 2009, 19, 8378.

[45] S.-W. Oh, S.-T. Myung, S.-M. Oh, K.-H. Oh, K. Amine, B. Scrosati, Y.-K. Sun, Adv. Mater., 2010, 22, 4842.

[46] J. Hassoun, D.-J. Lee, Y.-K. Sun, B. Scrosati, Solid State Ionics, 2011, 202, 36.

\section{Figures Caption}

Figure 1 a) Scanning electron microscopy (SEM) image of the GNPs water-based dispersion deposited on a $\mathrm{SiO}_{2}$ substrate. b) Raman spectrum of the GNPs. c) Thermal Gravimetric Analysis (TGA) in air with, in inset, a magnification normalized excluding the water contribution and d) corresponding derivative curve. e) Voltage profiles at the $1^{\text {st }}, 10^{\text {th }}, 100^{\text {th }}, 200^{\text {th }}, 300^{\text {th }}$ cycle and $f$ ) cycling response of a Li/ LP30/GNPs cell using a current of $744 \mathrm{~mA} \mathrm{~g}^{-1}$.

Figure 2 Electrochemical characterization of the Py $y_{1,4}$ TFSI-LiTFSI $0.2 \mathrm{~m}$ (black colored) and $\mathrm{Py}_{1,4}$ TFSI added by $30 \% \mathrm{w}: \mathrm{w}$ of EC-DMC (1:1), $0.2 \mathrm{~m}$ LiTFSI (red colored) electrolyte solutions. a) Arrhenius plot. b) Time evolution of the cell resistance and, in inset, corresponding Nyquist plot. 
c) Lithium deposition-stripping overvoltage and, in inset, curve magnification. d) Current-time curve following a dc polarization of $20 \mathrm{mV}$ and, in inset, impedance response before and after polarization.

Figure 3 a) Voltage profiles from $2^{\text {nd }}$ to $10^{\text {th }}$ of the Li/Py $y_{1,4}$ TFSI-(EC-DMC,1:1) 70-30, LiTFSI $0.2 \mathrm{~m} / \mathrm{GNPs}$ (current $74.4 \mathrm{mAg}^{-1}$ ) and b) of the Li/Py, ${ }_{1,4}$ TFSI-(EC-DMC,1:1) 70-30, LiTFSI 0.2m / $\mathrm{LiFePO}_{4}$ (current $17 \mathrm{~mA} \mathrm{~g}^{-1}$ ). c) Charge-discharge voltage profiles of the GNPs anode (red curve) and the $\mathrm{LiFePO}_{4}$ cathode (blue curve). d) Voltage profiles of the GNPs/Py, ${ }_{1,4}$ TFSI-(EC-DMC,1:1) 70-30, LiTFSI $0.2 \mathrm{~m} / \mathrm{LiFePO}_{4}$ full lithium ion battery from $1^{\text {st }}$ to $5^{\text {th }}$ cycles (current rate $17 \mathrm{~mA} \mathrm{~g}^{-1}$ vs. $\left.\mathrm{LiFePO}_{4}\right)$. 


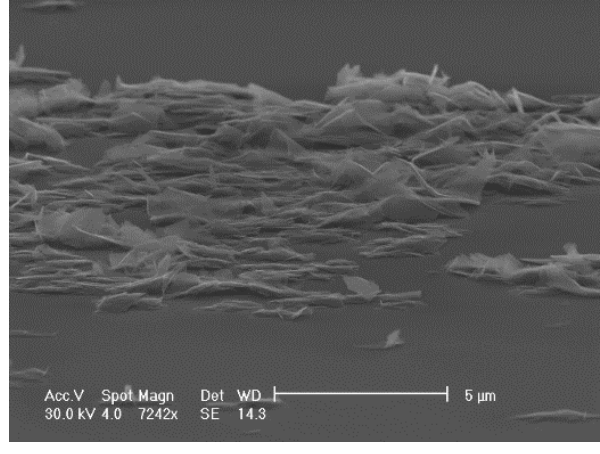

(a)

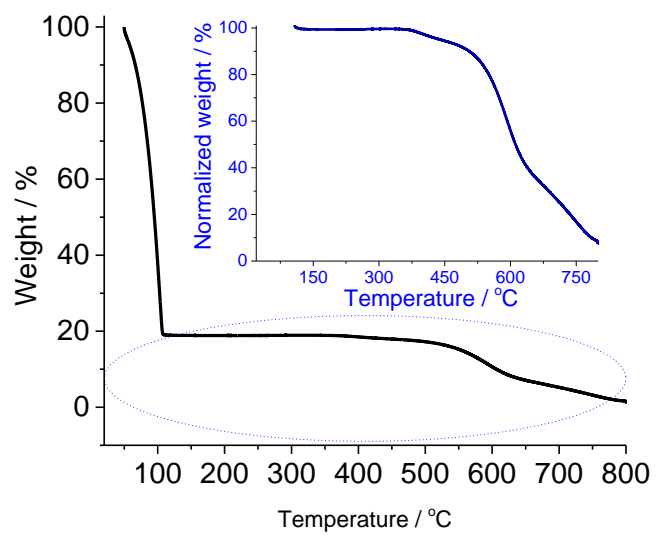

(c)

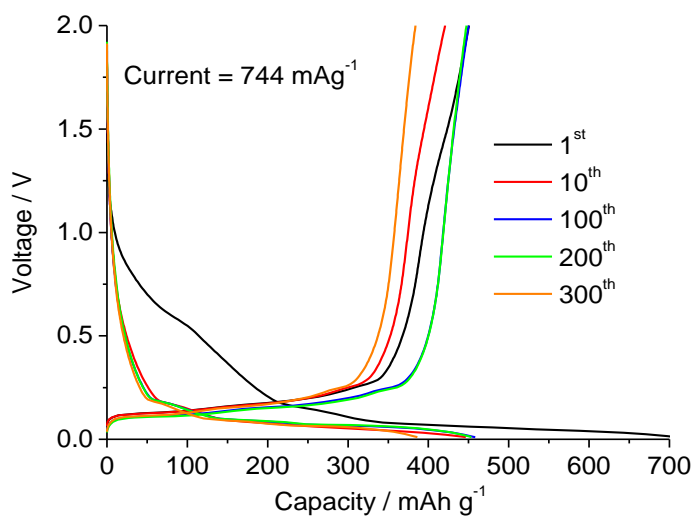

(e)

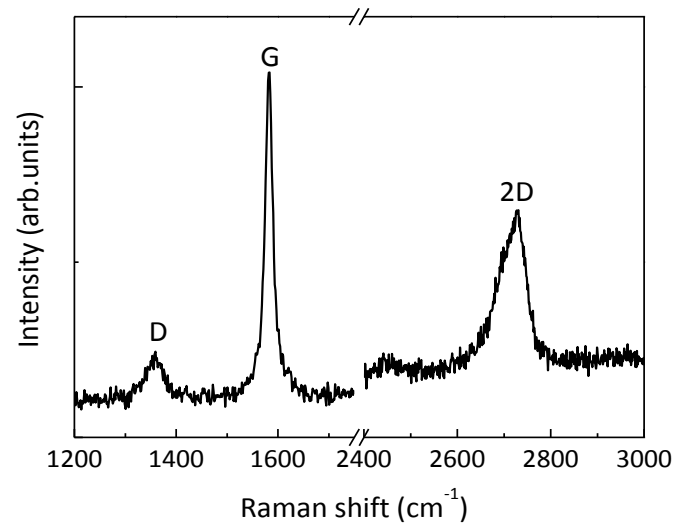

(b)

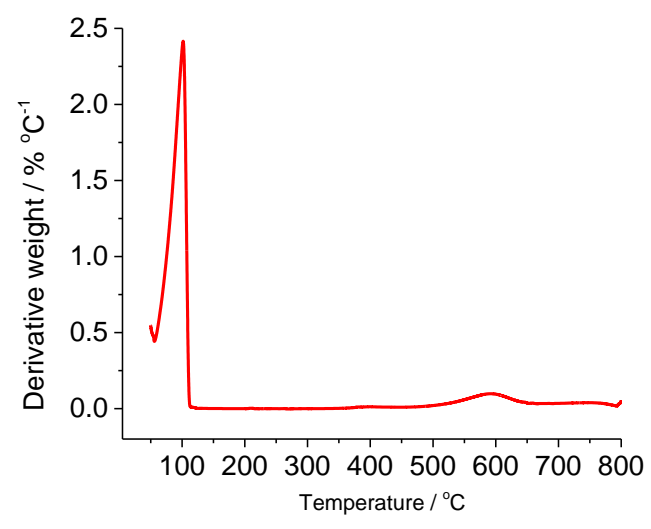

(d)

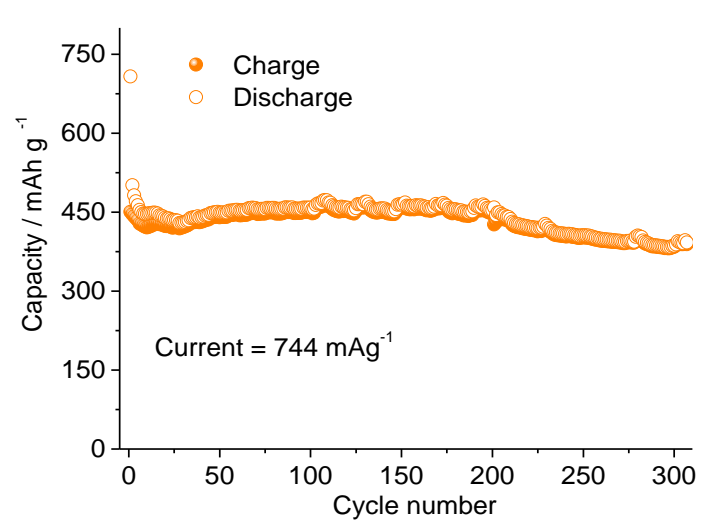

Figure 1 
1

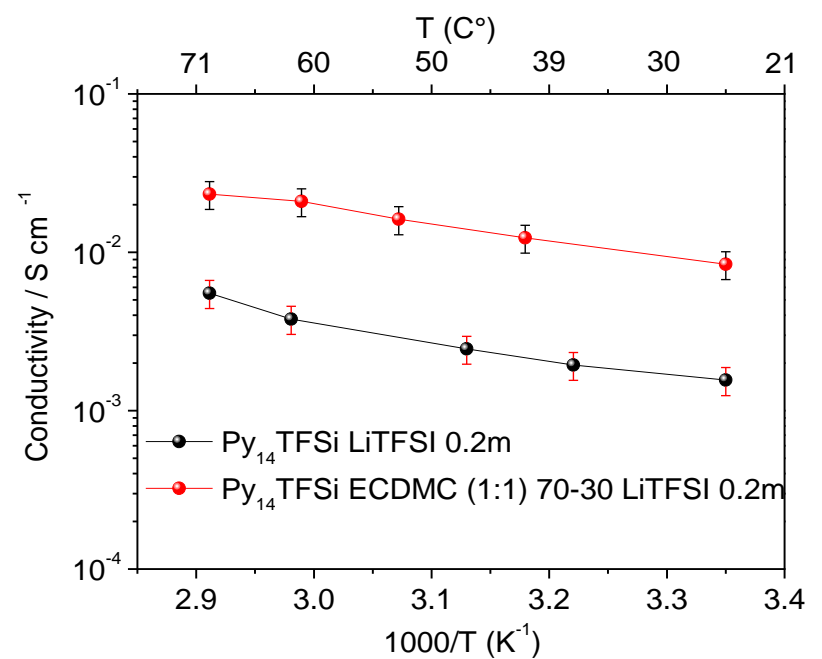

(a)
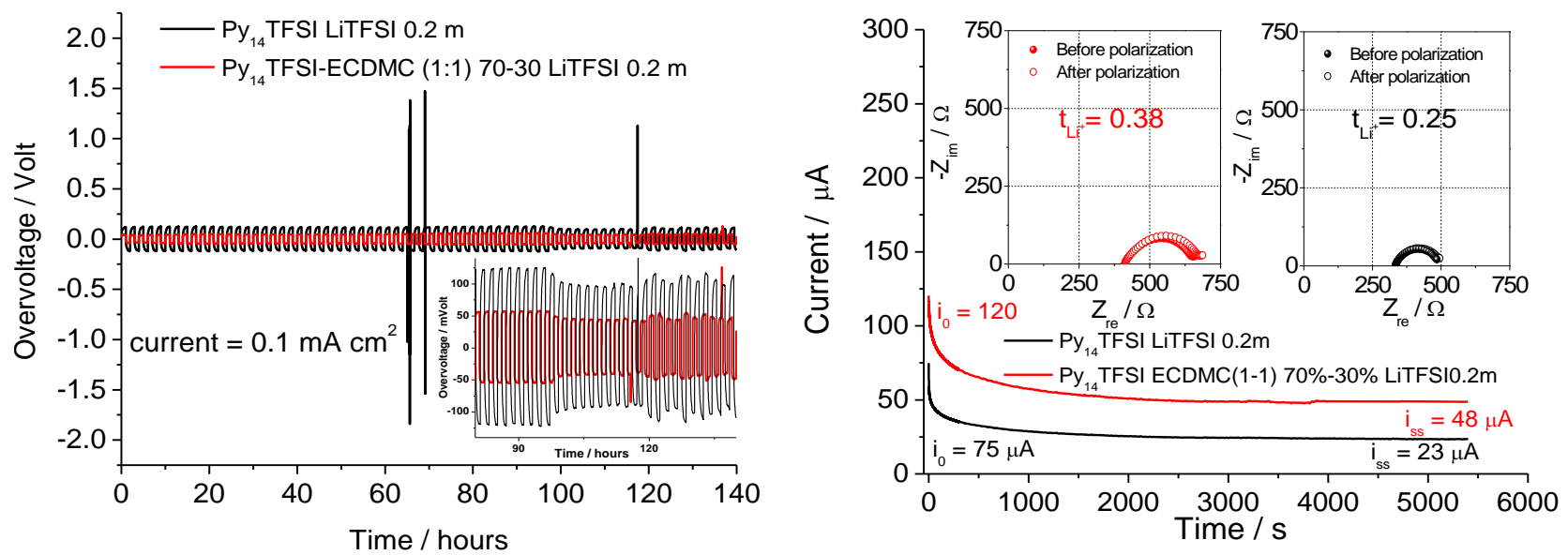

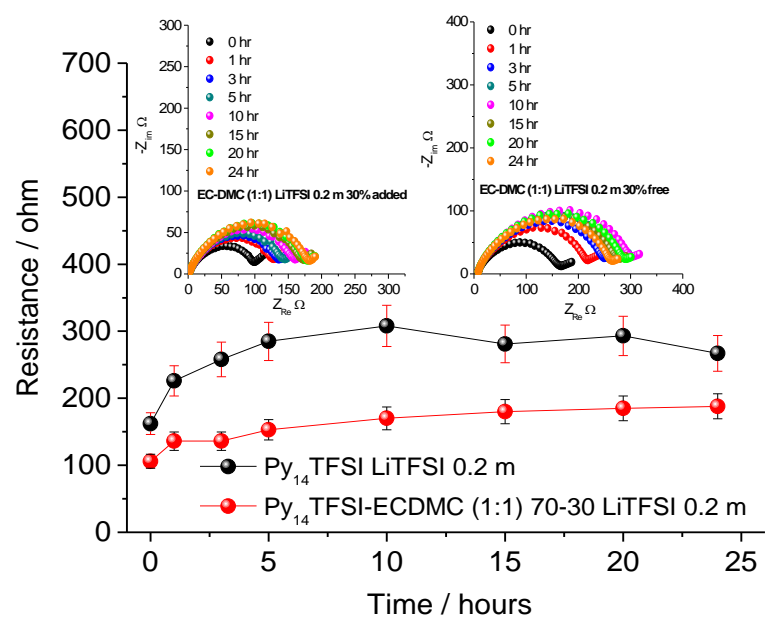

(b)

(d)

(c)

\section{Figure 2}




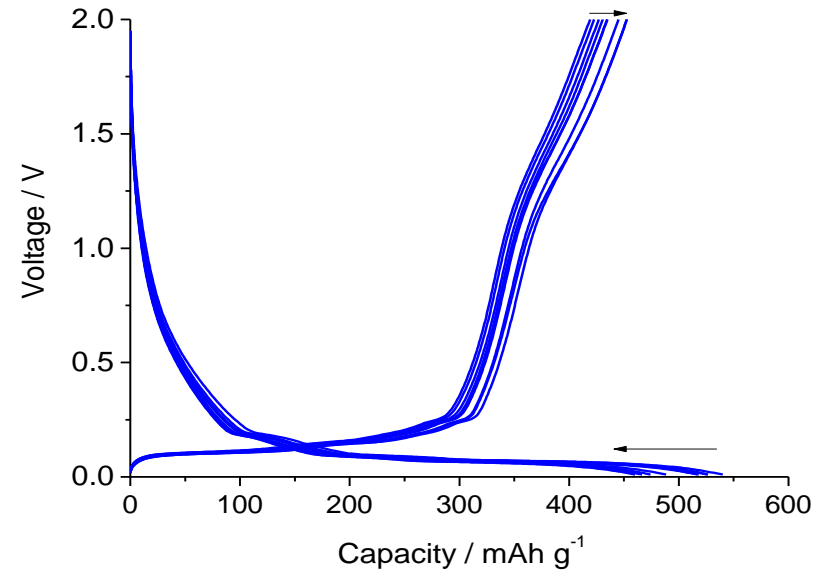

(a)

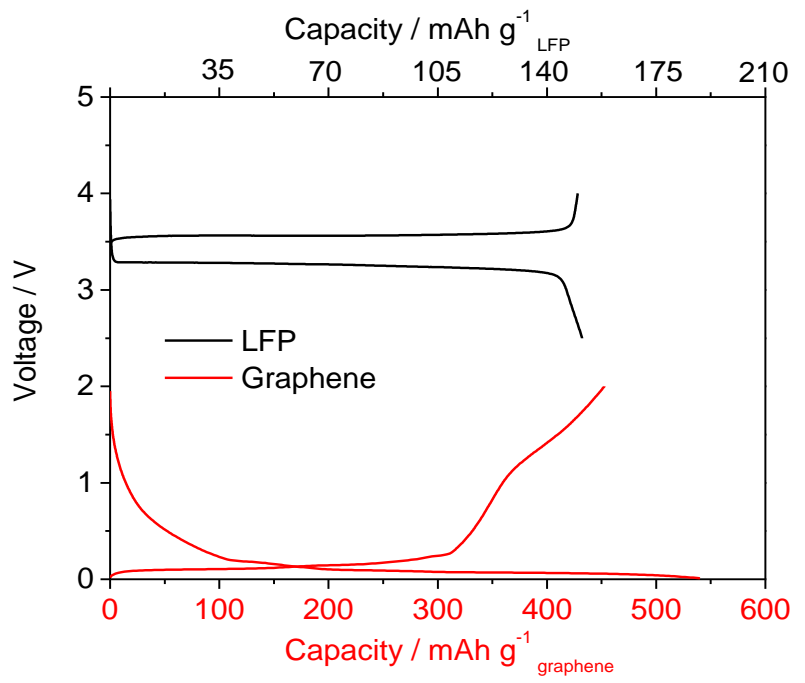

(c)

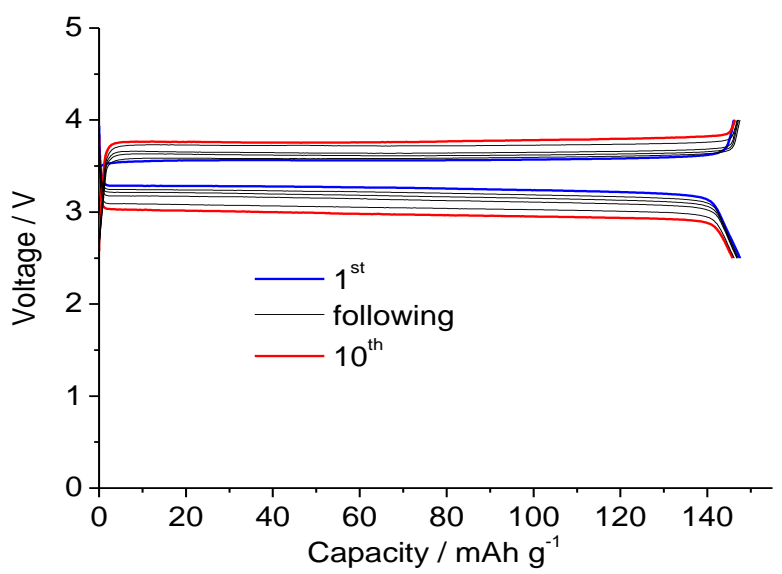

(b)

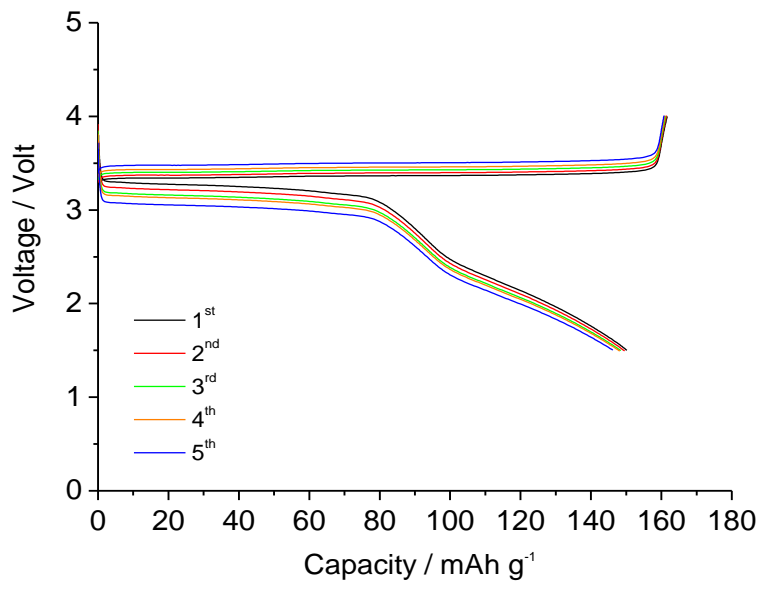

(d)

Figure 3 


\section{Table of contents}

$\mathrm{Cu}$-supported graphene nanoplatelets (GNPs) electrode is proposed as a high performance lithium ion battery anode. The electrode is prepared by easy-to-handle aqueous ink cast as homogeneous, micrometric flakes. A GNPs/Py $y_{1,4}$ TFSI-LiTFSI-EC:DMC/LiFePO 4 advanced lithium-ion battery delivers a capacity of $150 \mathrm{mAh} \mathrm{g}^{-1}$ with an efficiency approaching $100 \%$.

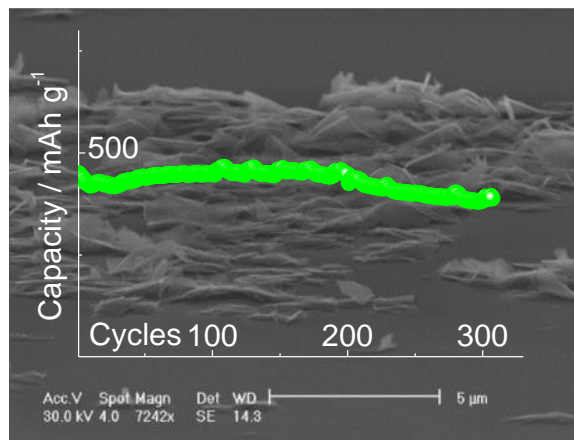


Figure 1
Click here to download Production Data: Figure1.tif 
Figure 2
Click here to download Production Data: Figure2.tif Click here to download Production Data: Figure2 tif

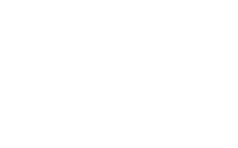

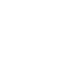
(1)

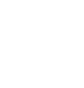

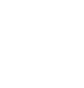
(1) (1) (1) (1)

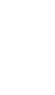
(1)

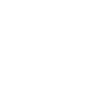

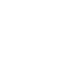

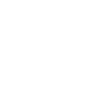
. (1) . .

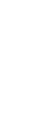
. . . . . non

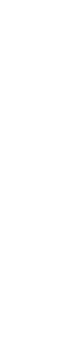

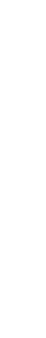
non $n^{2}+x^{2}$

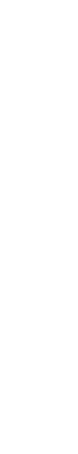
(1)

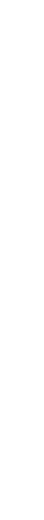

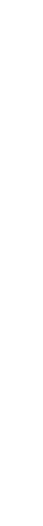


Figure 3
Click here to download Production Data: Figure3.tif

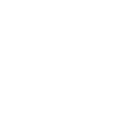

.

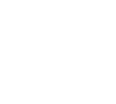

Click here to download Production Data: Figure 3 iff

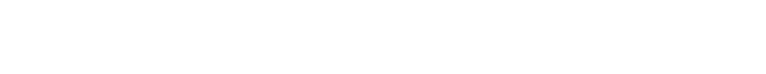


Table of Contents image
Click here to download Production Data: TOC.tif

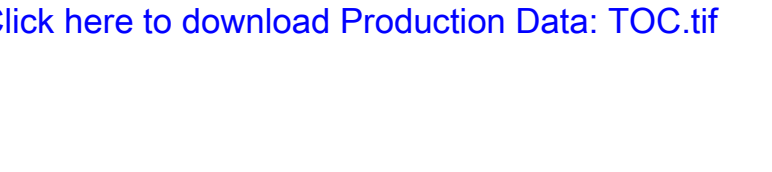

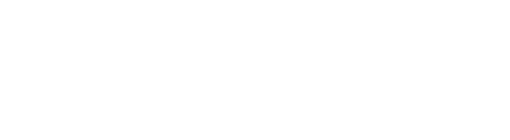

